Figure S1 - Spectrally resolved FLIM images from a sample of normal skin taken at several depths. (Figure $1 \mathrm{j}-\mathrm{n}$ shows only the $425-525 \mathrm{~nm}$ (green) channel of this data.)

\title{
Spectral Channel
}

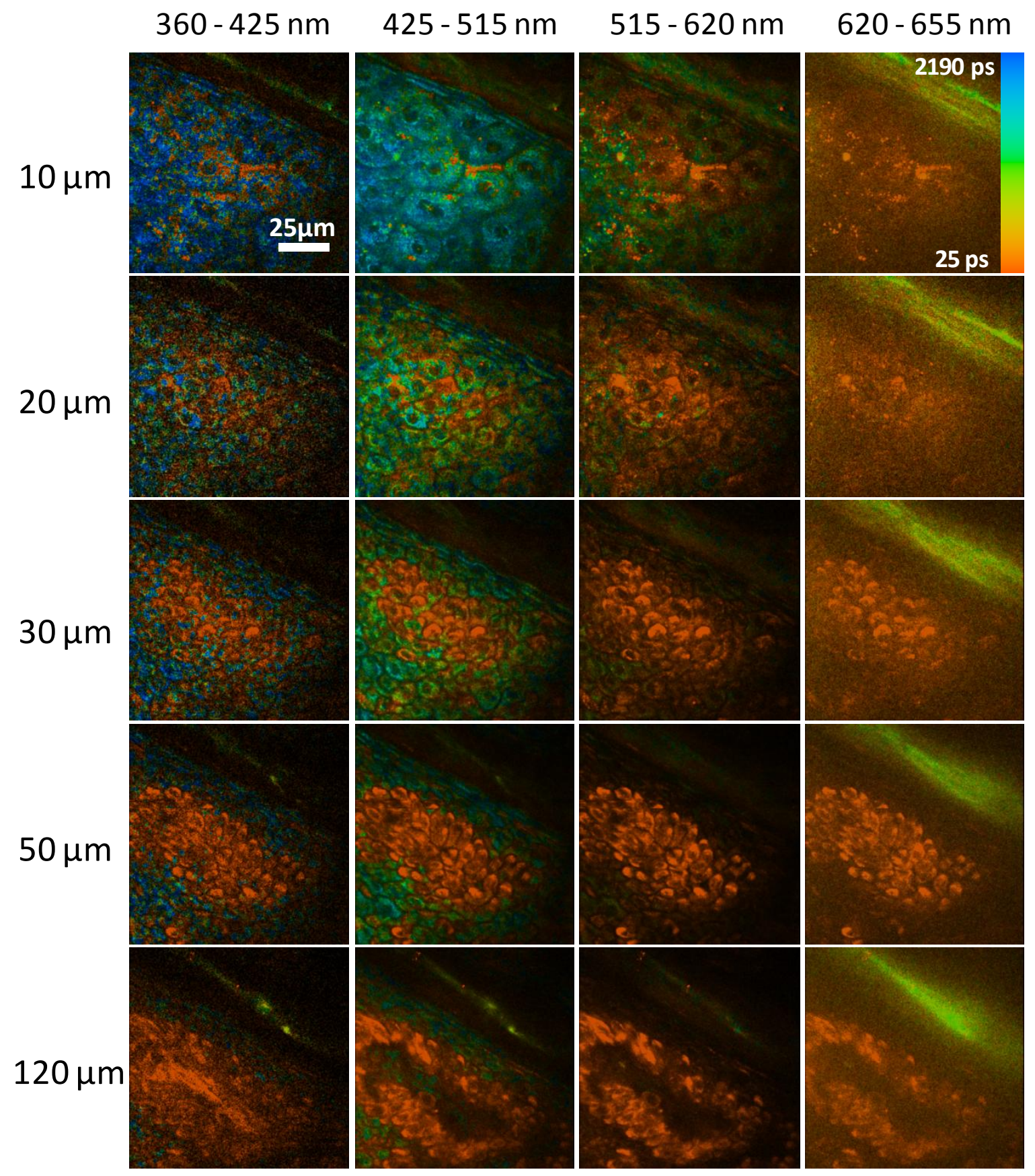

